Note

\title{
Comprehensive T-matrix reference database: A 2007-2009 update
}

\author{
Michael I. Mishchenko ${ }^{\mathrm{a}, *}$, Nadia T. Zakharova ${ }^{\mathrm{b}}$, Gorden Videen ${ }^{\mathrm{c}}$, \\ Nikolai G. Khlebtsov ${ }^{\mathrm{d}}$, Thomas Wriedt ${ }^{\mathrm{e}}$ \\ a NASA Goddard Institute for Space Studies, 2880 Broadway, New York, NY 10025, USA \\ b Sigma Space Partners, 2880 Broadway, New York, NY 10025, USA \\ c US Army Research Laboratory, AMSRL-IS-EE, 2800 Powder Mill Road, Adelphi, MD 20783-1197, USA \\ d Institute of Biochemistry and Physiology of Plants and Microorganisms, Russian Academy of Sciences, 13 Entuziastov Ave., 410015 Saratov, Russia \\ e Institut für Werkstofftechnik, Badgasteiner Str. 3, D-28359 Bremen, Germany
}

\section{A R T I C L E I N F O}

Article history:

Received 26 October 2009

Received in revised form

28 October 2009

Accepted 2 November 2009

\section{Keywords:}

Electromagnetic scattering

$T$-matrix method

\begin{abstract}
A B S T R A C T
The T-matrix method is among the most versatile, efficient, and widely used theoretical techniques for the numerically exact computation of electromagnetic scattering by homogeneous and composite particles, clusters of particles, discrete random media, and particles in the vicinity of an interface separating two half-spaces with different refractive indices. This paper presents an update to the comprehensive database of $T$ matrix publications compiled by us previously and includes the publications that appeared since 2007. It also lists several earlier publications not included in the original database.
\end{abstract}

Published by Elsevier Ltd.

\section{Introduction}

As evidenced by numerous citations, the original database of $T$-matrix publications [1-3] has proved to be a very useful research tool. Its customers have indicated to us many times that they would like to see a continually updated version, which appears to be quite reasonable given the steadily increasing popularity of the $T$-matrix approach (Fig. 1). As in the two previous updates $[2,3]$, the way in which we accommodate this request is twofold. First, we have made the necessary corrections and straightforward updates in the original database [1-3], and the result has been posted at http://www.giss.nasa.gov/staff/mmishchenko/publications/. Second, this new paper lists several earlier publications that had been omitted inadvertently in [1-3] as well as the most recent $T$-matrix publications that have appeared since 2007. The total number of newly added publications is 253 [4-256].

\footnotetext{
* Corresponding author. Fax: +12126785622.

E-mail address: mmishchenko@giss.nasa.gov (M.I. Mishchenko).
}

As in [1-3], the database is kept at a manageable size by adhering to the following general restrictions:

- With a few important exceptions, the database contains only publications dealing with electromagnetic scattering.

- Publications on scattering by isolated infinite cylinders and systems of parallel infinite cylinders in unbounded space are excluded.

- Publications on the Lorenz-Mie theory and its various extensions to radially inhomogeneous spherically symmetric scatterers are excluded.

- The database contains only references to books, peerreviewed book chapters, and peer-reviewed journal papers.

Also, we have continued to use the following operational definition of the $T$-matrix method:

In the $T$-matrix method, the incident and scattered electric fields are expanded in series of suitable vector spherical wave functions, and the relation between the 


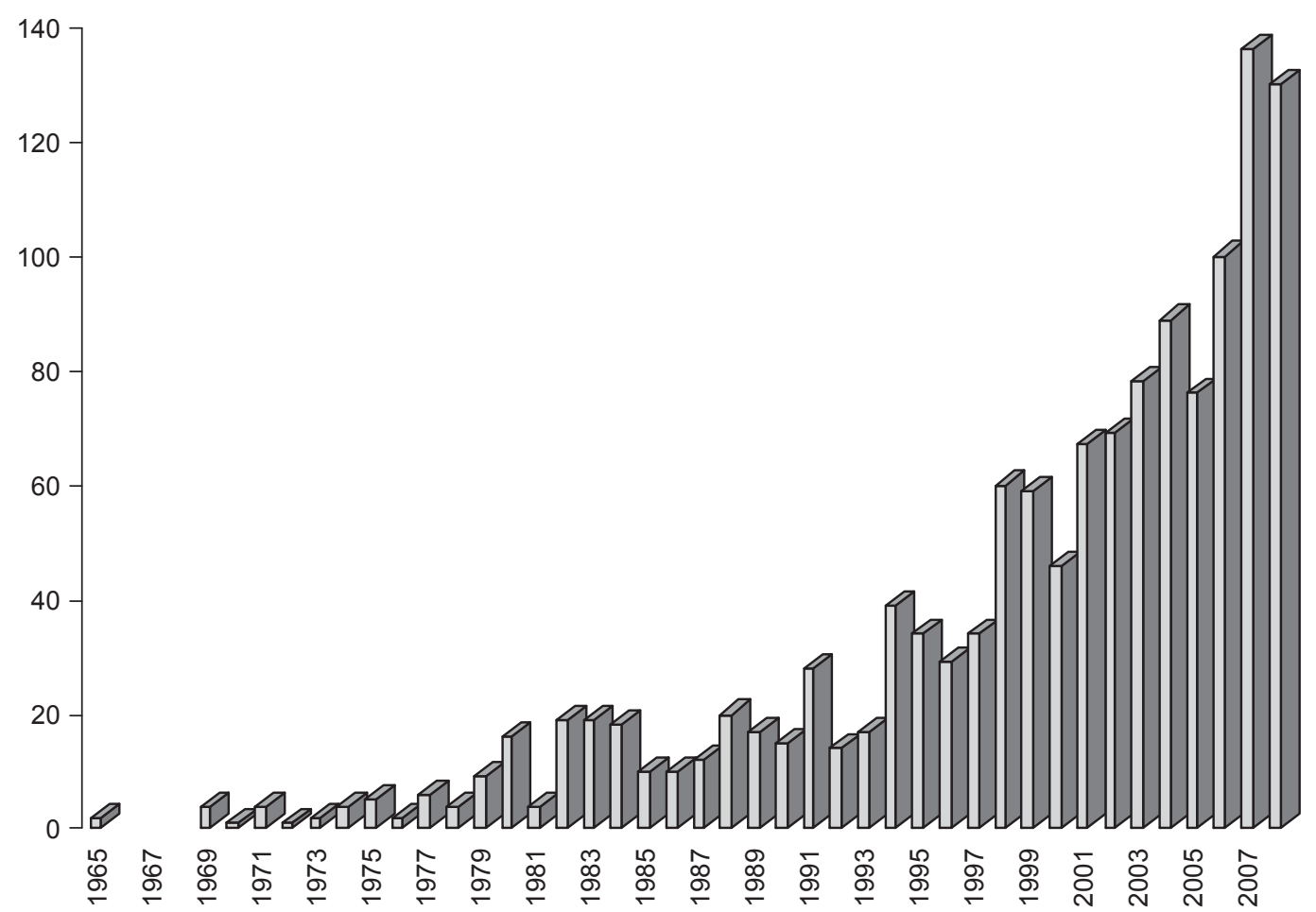

Fig. 1. Annual frequency distribution of the $T$-matrix publications.

columns of the respective expansion coefficients is established by means of a transition matrix (or $T$ matrix). This concept can be applied to the entire scatterer as well as to separate parts of a composite scatterer.

This definition is consistent with the general methodology pursued in [257-259] and is significantly wider than the original notion of the extended boundary condition method (EBCM) [260]. According to our terminology, EBCM is just one of many potential techniques for the actual numerical calculation of the $T$ matrix.

As in the original database, the use of the reference list is facilitated by classifying the various references into a set of narrower subject categories (Sections 2 and 3). This set is largely the same as in [1-3]. However, several original categories are not populated since no relevant publications have appeared during the past three years.

As previously, we do not assess or discuss the validity and importance of the results described in the specific $T$ matrix publications forming the reference list, which means that the inclusion of a publication does not constitute any formal endorsement or quality certification on our part. As before, we plan to maintain the updated version of the combined database on-line and, therefore, ask the readers to communicate to us corrections and missing references to existing and future publications on the $T$-matrix method and its practical applications.

\section{Particles in infinite homogeneous space}

\subsection{Books}

[252].

\subsection{Reviews}

$[83,176]$.

2.3. Extended boundary condition method and its modifications and generalizations

$[108,176,181,231,236,237,240,241,252]$.

2.4. T-matrix theory and computations for bi-isotropic, anisotropic, and chiral scatterers

$$
[11,23,181,186] \text {. }
$$

2.5. Superposition T-matrix method and its modifications, including related mathematical tools

$$
[39,73,236,237,240,241]
$$

2.6. T-matrix theory of electromagnetic scattering by periodic arrays of particles and photonic crystals

$[61,91,92,93,149,197,211]$ 
2.7. T-matrix theory and computations of electromagnetic scattering by discrete random media

$$
[11,14,120,123,127,142,205-207,221] \text {. }
$$

2.8. Relation of the T-matrix method to other theoretical approaches

$[98,99,111,176,220,232,252]$.

2.9. Symmetry properties of the T matrix and analytical ensemble-averaging approaches

$[22,83,111,150]$.

2.10. Convergence and efficiency of various implementations of the T-matrix method

$[26,106,159,223,231,232,236,237,239,240,241,252]$.

2.11. T-matrix calculations for homogeneous spheroids

$[4,9,16,19,20,21,26,32,34-36,38,42,43,46,47,51,53,55-59$, $62,63,66,69,71,77,81,84,85,87-89,90,96,97,107,114,115,117$, $118,121,124,125,126,128,129,131-133,136,140,144-148$, 151,152,163,165-167,169-175,177,178,182,185,187,190, $193,194,197,200,201,214,215,216,218,223-225,227,229,230$, $233,234,238,245,252,253]$.

2.12. T-matrix calculations for Chebyshev and generalized Chebyshev particles

$[105,121,128,129,203,204,230,252]$.

2.13. T-matrix calculations for finite circular cylinders

$[21,36,51,57,61,67,78,80,103,128,129,145,147,149,158$, $180,211,219,222,226,227,235,237,240,241,252]$.

2.14. T-matrix calculations for various rotationally symmetric particles

[75,86-88,94,156,157,161,188,195].

2.15. T-matrix calculations for ellipsoids, polyhedral scatterers, and other particles lacking axial symmetry

$[180,181,236,237]$.

2.16. T-matrix calculations for layered and composite particles

$[6,79,154,155,160,186,237]$.

2.17. T-matrix calculations for clusters of homogeneous spheres

$[4,5,13-15,25,28-31,37,40,41,44,45,48-50,54,72,74,82$, $92,93,102,110,112,119,120,122,123,125,134,137,141-143$,
$146,153,162,164,183,184,192,197,198,199,202,206-210$ 212-214,217,221,227,228,242-244,246,247,249,250].

2.18. T-matrix calculations for clusters of layered spheres

$[91,92,93,197,217]$

2.19. T-matrix calculations for clusters of nonspherical monomers

$[61,149,197,237]$

2.20. T-matrix calculations for particles with one or several (eccentric) inclusions

[160].

2.21. T-matrix calculations of optical resonances in nonspherical particles and particle clusters

$[4,5,15,18,26,40,48,49,61,72,74,79,86-88,92-94,100$, $154,155,164,169,183,184,197,198,199,211,228,233]$.

2.22. T-matrix calculations of optical forces and torques on small particles

$[12,24,25,42,95,113,138,139,189,190,191]$.

2.23. T-matrix calculations of internal, surface, and local fields

[13,23,26,31,37,40,112,134,153,162,198,206,207,247].

2.24. Illumination by focused beams and non-plane waves

$[25,70,138,189,190,191]$.

2.25. Use of T-matrix calculations for testing other theoretical techniques

$[27,34,54,68,69,78,85,102,103,109,131,152,167,202,210$, 212-214,216,218,221,223,236,238,244,249,250].

2.26. Comparisons of T-matrix and effective-mediumapproximation results

$[23,102]$.

2.27. Comparisons of T-matrix and controlled laboratory results

[28-30,37,61,64-66,91,94,119,167-169,178,243].

2.28. Use of T-matrix calculations for analyzing laboratory data

$[4-6,8,9,34,35,38,56,62,63,67,86,132,171,173,174,193$, $200,201,226,227,246]$. 
2.29. T-matrix modeling of scattering properties of mineral aerosols in the terrestrial atmosphere and soil particles

$[16,43,58,59,71,81,107,114,118,126,128,129,140,144$ $147,148,170,172,215,227,229,234]$.

2.30. T-matrix modeling of scattering properties of carbonaceous and soot aerosols and soot-containing aerosol and cloud particles

$[6,107,110,146,227,249,250]$.

2.31. T-matrix modeling of scattering properties of cirrus cloud particles

[103,135,145,177,180,193,194,196,226,227].

2.32. T-matrix modeling of scattering properties of hydrometeors

$[7,10,19,20,33,46,60,97,104,105,115,116,130,136,163$, $179,187,195,203,204,214,224,225,245,248,251,253,254]$.

2.33. T-matrix modeling of scattering properties of terrestrial stratospheric aerosol and cloud particles

[166].

2.34. T-matrix modeling of scattering properties of noctilucent cloud particles

$[17,21,77,175,222]$.

2.35. T-matrix modeling of scattering properties of aerosol and cloud particles in planetary atmospheres

$[51,84,151,192,208,219,235]$.

2.36. T-matrix modeling of scattering properties of interstellar, interplanetary, cometary, planetary regolith, and planetary ring particles

$[44,45,53,96,101,117,121,122,127,162,202,205,206$, $207,216]$.

2.37. T-matrix computations for industrial and military applications

$[14,69,137,173,174,217]$.

\subsection{T-matrix computations for biomedical applications}

$[4,5,8,9,34,35,38,41,47,55-57,62,63,67,69,80,88,132$, $133,136,171,173,174,188,200,201,209,218,238]$.

2.39. T-matrix computations of anisotropic and aggregation properties of colloids and other disperse media

$[89,132]$.

\section{Particles near infinite interfaces}

3.1. Spherically symmetric particles

$[52,76,255]$

3.2. Non-spherically symmetric finite particles and particle aggregates

$[52,211,255,256]$.

3.3. Finite particles on incident side of planar interface

$[52,211,255,256]$.

3.4. Tools for particle characterization

$[76,256]$.

\section{Acknowledgments}

We thank Josefina Mora and Zoe Wai for helping to obtain copies of publications that were not readily accessible. This project was sponsored by the NASA Radiation Sciences Program managed by Hal Maring.

\section{References}

[1] Mishchenko MI, Videen G, Babenko, VA, et al. T-matrix theory of electromagnetic scattering by particles and its applications: a comprehensive reference database. JQSRT 2004;88:357-406.

[2] Mishchenko MI, Videen G, Babenko, VA, et al. Comprehensive T-matrix reference database: a 2004-06 update. JQSRT 2007;106: 304-324.

[3] Mishchenko MI, Videen G, Khlebtsov, NG, et al. Comprehensive T-matrix reference database: a 2006-07 update. JQSRT 2008;109:144760.

[4] Aaron J, de la Rosa E, Travis, K, et al. Polarization microscopy with stellated gold nanoparticles for robust, in-situ monitoring of biomolecules. Opt Express 2008;16:2153-67.

[5] Aaron J, Travis K, Harrison N, Sokolov, K, et al. Dynamic imaging of molecular assemblies in live cells based on nanoparticle plasmon resonance coupling. Nano Lett 2009;9:3612-8.

[6] Abo Riziq A, Trainic M, Erlick, C, et al. Extinction efficiencies of coated absorbing aerosols measured by cavity ring down aerosol spectrometry. Atmos Chem Phys 2008;8:1823-33.

[7] Adams IS, Gaiser P, Jones WL. Simulation of the Stokes vector in inhomogeneous precipitation. Radio Sci 2008;43:RS5006.

[8] Airola MB, Boggs NT, Jackman, J, et al. Spectral refractive index and extinction cross-section of BG spores. Proc SPIE 2005;5795:134-41.

[9] Amoozegar C, Giacomelli MG, Keener, JD, et al. Expermental verification of $T$-matrix-based inverse light scattering analysis for assessing structure of spheroids as models of cell nuclei. Appl Opt 2009;48:D20-5.

[10] Anagnostou MN, Anagnostou EN, Vulpiani, G, et al. Evaluation of Xband polarimetric-radar estimates of drop-size distributions from coincident S-band polarimetric estimates and measured raindrop spectra. IEEE Trans Geosci Remote Sens 2008;46:3067-75.

[11] Apparao RT, Varadan VV, Varadan VK. Theoretical modeling of chiral composites. Proc SPIE 1991;1558:2-13.

[12] Asavei T, Loke VLY, Barbieri, M, et al. Optical angular momentum transfer to microrotors fabricated by two-photon photopolymerization. New J Phys 2009;11:093021.

[13] Auger J-C, Stout B. Local field intensity in aggregates illuminated by diffuse light: T matrix approach. Appl Opt 2008;47:2897-905.

[14] Auger JC, Martinez VA, Stout B. Theoretical study of the scattering efficiency of rutile titanium dioxide pigments as a function of their spatial dispersion. J Coat Technol Res 2009;6:89-97. 
[15] Ausman LK, Schatz GC. On the importance of incorporating dipole reradiation in the modeling of surface enhanced Raman scattering from spheres. J Chem Phys 2009;31:084708.

[16] Bailey J, Ulanowski Z, Lucas, PW, et al. The effect of airborne dust on astronomical polarization measurements. Mon Not R Astron Soc 2008;386:1016-22.

[17] Bailey SM, Thomas GE, Rusch, DW, et al. Phase functions of polar mesospheric cloud ice as observed by the CIPS instrument on the AIM satellite. J Atmos Solar Terrestrial Phys 2009;71:373-80.

[18] Barnes WL. Comparing experiment and theory in plasmonics. J Opt A Pure Appl Opt 2009;11:114002.

[19] Battaglia A, Kobayashi S, Tanelli, S, et al. Multiple scattering effects in pulsed radar systems: an intercomparison study. J Atmos Oceanic Technol 2008;25:1556-67.

[20] Battaglia A, Saavedra P, Simmer C, Rose T. Rain observations by a multifrequency dual-polarized radiometer. IEEE Geosci Remote Sens Lett 2009;6:354-8.

[21] Baumgarten G, Fiedler J, Lübken F-J, von Cossart G. Particle properties and water content of noctilucent clouds and their interannual variation. J Geophys Res 2008;113:D06203.

[22] Berg MJ, Chakrabarti A, Sorensen CM. General derivation of the total electromagnetic cross sections for an arbitrary particle. JQSRT 2009;110:43-50.

[23] Bogaert I, Peeters J, Olyslager F. Homogenization of metamaterials using full-wave simulations. Metamaterials 2008;2:101-12.

[24] Borghese F, Denti P, Saija R, latì MA. Optical trapping of nonspherical particles in the $T$-matrix formalism: erratum. Opt Express 2007;15:14618.

[25] Borghese F, Denti P, Saija, R, et al. Radiation torque and force on optically trapped linear nanostructures. Phys Rev Lett 2008;100: 163903.

[26] Boyack R, Le Ru EC. Investigation of particle shape and size effects in SERS using $T$-matrix calculations. Phys Chem Chem Phys 2009; 11:7398-405.

[27] Boyde L, Chalut KJ, Guck J. Interaction of Gaussian beam with nearspherical particle: an analytic-numerical approach for assessing scattering and stresses. J Opt Soc Am A 2009;26:1815-27.

[28] Bunkin NF, Suyazov NV, Shkirin, AV, et al. Nanoscale structure of dissolved air bubbles in water as studied by measuring the elements of the scattering matrix. J Chem Phys 2009;130:134308.

[29] Bunkin NF, Suyazov NV, Shkirin, AV, et al. Cluster structure of stable dissolved gas nanobubbles in highly purified water. J Exp Theor Phys 2009;108:800-16.

[30] Bunkin NF, Suyazov NF, Shkirin, AV, et al. Determination of the microstructure of gas bubbles in highly purified water by measuring the elements of the laser radiation scattering matrix. Quantum Electron 2009;39:367-81.

[31] Cacciola A, Cecchi-Pestellini C, Saija, R, et al. Ultraviolet radiation inside interstellar grain aggregates. III. Fluffy grains. Astrophys J 2009;701:1426-35.

[32] Cai W, Ma L. Information content of scattering measurements and characterization of spheroids. J Aerosol Sci 2008;39:1032-9.

[33] Chaboureau J-P, Söhne N, Pinty, J-P, et al. A midlatitude precipitating cloud database validated with satellite observations. J Appl Meteorol Climatol 2008;47:1337-53.

[34] Chalut KJ, Chen S, Finan, JD, et al. Label-free, high-throughput measurements of dynamic changes in cell nuclei using angleresolved low coherence interferometry. Biophys J 2008;94:494856.

[35] Chalut KJ, Giacomelli MG, Wax A. Application of Mie theory to assess structure of spheroidal scattering in backscattering geometries. J Opt Soc Am A 2008;25:1866-74.

[36] Chen G, Yang P, Kattawar GW. Application of the pseudospectral time-domain method to the scattering of light by nonspherical particles. J Opt Soc Am A 2008;25:785-90.

[37] Chen S-Y, Lazarides AA. Quantitative amplification of Cy5 SERS in 'Warm Spots' created by plasmonic coupling in nanoparticle assemblies of controlled structure. J Phys Chem C 2009;113:12167-75.

[38] Chernyshev AV, Tarasov PA, Semianov, KA, et al. Erythrocyte lysis in isotonic solution of ammonium chloride: theoretical modeling and experimental verification. J Theor Biol 2008;251:93-107.

[39] Chew WC. Vector addition theorem and its diagonalization. Commun Comput Phys 2008;3:330-41.

[40] Chien W-Y, Szkopek T. Multiple-multipole simulation of optical near-fields in discrete metal nanosphere assemblies. Opt Express 2008;16:1820-35.

[41] Cohen FS, Taslidere E, Hari DS, Murthy S. Stochastic decomposition method for modeling the scattered signal reflected of mucosal tissues. J Biomed Opt 2008;13:054039.
[42] Conover BL, Escuti MJ. Anisotropic particle motion in optical landscapes modeled via the $T$-matrix optical scattering approach. Proc SPIE 2008;7038:703819.

[43] Cuesta J, Flamant PH, Flamant C. Synergetic technique combining elastic backscatter lidar data and sunphotometer AERONET inversion for retrieval by layer of aerosol optical and microphysical properties. Appl Opt 2008;47:4598-611.

[44] Das HS, Das SR, Paul, T, et al. Aggregate model of cometary dust: an application to comet Levy 1990XX. Mon Not R Astron Soc 2008; 389:787-91.

[45] Das HS, Das SR, Sen AK. Aggregate dust model to describe polarization properties of Comet Hale-Bopp. Mon Not R Astron Soc 2008;390:1195-9.

[46] Defer E, Prigent C, Aires, F, et al. Development of precipitation retrievals at millimeter and sub-millimeter wavelengths for geostationary satellites. J Geophys Res 2008;113:D08111.

[47] Devarakonda V, Manickavasagam S. Polarized light scattering technique for morphological characterization of waterborne pathogens. Proc SPIE 2009;7306:73061B.

[48] Deych LI, Schmidt C, Chipouline, A, et al. Optical coupling of fundamental whispering-gallery modes in bispheres. Phys Rev A 2008;77:051801.

[49] Deych LI, Schmidt C, Chipouline, A, et al. Propagation of the fundamental whispering gallery modes in a linear chain of microspheres. Appl Phys B 2008;93:21-30.

[50] Ding KH. Light scattering of fractal aerosol aggregates using T-matrix method. Proc SPIE 1992;1688:144-51.

[51] Dlugach JM, Mishchenko MI. Photopolarimetry of planetary atmospheres: what observational data are essential for a unique retrieval of aerosol microphysics?. Mon Not $\mathrm{R}$ Astron Soc 2008;384:64-70.

[52] Doicu A, Schuh R, Wriedt T. Scattering by particles on or near a plane surface. Light Scattering Rev 2008;3:109-30.

[53] Draine BT, Fraisse AA. Polarized far-infrared and submillimeter emission from interstellar dust. Astrophys J 2009;696:1-11.

[54] Dreyfus R, Lacoste D, Bibette J, Baudry J. Measuring colloidal forces with the magnetic chaining technique. Eur Phys J E 2009; 28:113-23.

[55] Duncan DD, Thomas ME. Particle shape as revealed by spectral depolarization. Proc SPIE 2008;6864:68640G.

[56] Duncan DD, Gladdish JC, Markway BD. Tissue morphology from spectral polarimetry. Proc SPIE 2008;6858:685809.

[57] Dyatlov GV, Gilev KV, Semyanov KA, Maltsev VP. The scanning flow cytometer modified for measurement of two-dimensional lightscattering pattern of individual particles. Meas Sci Technol 2008 19:015408.

[58] Feng Q, Yang P, Kattawar, GW, et al. Effects of particle nonsphericity and radiation polarization on retrieving dust properties from MODIS observations. J Aerosol Sci 2009;40:776-89.

[59] Fu Q, Thorsen TJ, Su, J, et al. Test of Mie-based single-scattering properties of non-spherical dust aerosols in radiative flux calculations. JQSRT 2009;110:1640-53.

[60] Gallus Jr. WA, Pfeifer M. Intercomparison of simulations using 5 WRF microphysical schemes with dual-polarization data for a German squall line. Adv Geosci 2008;16:109-16.

[61] Gantzounis G, Stefanou N, Papanikolaou N. Optical properties of periodic structures of metallic nanodisks. Phys Rev B 2008 77:035101

[62] Giacomelli MG, Chalut KJ, Ostrander JH, Wax A. Application of the $T$-matrix method to determine the structure of spheroida cell nuclei with angle-resolved light scattering. Opt Lett 2008; 33:2452-4

[63] Giacomelli M, Chalut K, Ostrander J, Wax A. T-matrix based inverse light scattering analysis using angle resolved low coherence interferometry. Proc SPIE 2009;7187:71870L

[64] Gogoi A, Ahmed GA. A T-matrix approach for morphological characterization of spherical nanoparticles using laser. Indian J Phys 2008;82:567-70.

[65] Gogoi A, Ahmed GA, Choudhury A. Nonaparticle size characterization by laser light scattering. Indian J Phys 2009;83:473-7.

[66] Gogoi A, Choudhury A, Stanciu GA, Ahmed GA. Construction of multidetector array incorporated laser-based scattering system for ultrafine $\mathrm{TiO}_{2}$ characterization. J Opt 2009;38:67-74.

[67] Gong W, Si K, Sheppard CJR. Modeling phase functions in biological tissue. Opt Lett 2008;33:1599-601.

[68] Gruy F. Light-scattering cross section as a function of pair distribution density. JQSRT 2009;110:240-6.

[69] Hahn DV, Limsui D, Joseph, RI, et al. Shape characteristics of biological spores. Proc SPIE 2008;6954:69540W. 
[70] Han G, Han Y, Liu J, Zhang Y. Scattering of an eccentric sphere arbitrarily located in a shaped beam. J Opt Soc Am B 2008;25:206472.

[71] Hansell RA, Liou KN, Ou, SC, et al. Remote sensing of mineral dust aerosol using AERI during the $\mathrm{UAE}^{2}$ : a modeling and sensitivity study. J Geophys Res 2008;113:D18202.

[72] Harris N, Arnold MD, Blaber MG, Ford MJ. Plasmonic resonances of closely coupled gold nanosphere chains. J Phys Chem C 2009; 113:2784-91.

[73] He B, Chew WC. Addition theorem. In: Ammari H, editor. Modeling and computations in electromagnetics. Berlin: Springer; 2008. p. 203-26.

[74] Heifetz A, Simpson JJ, Kong, S-C, et al. Subdiffraction optical resolution of a gold nanosphere located within the nanojet of a Mie-resonant dielectric microsphere. Opt Express 2007;15:17334-42.

[75] Hellmers J, Riefler N, Wriedt T, Eremin YuA. Light scattering simulation for the characterization of sintered silver nanoparticles. JQSRT 2008;109:1363-73.

[76] Hertlein C, Riefler N, Eremina, E, et al. Experimental verification of an exact evanescent light scattering model for TIRM. Langmuir $2008 ; 24: 1-4$.

[77] Hervig ME, Gordley LL, Stevens, $\mathrm{MH}$, et al. Interpretation of SOFIE PMC measurements: cloud identification and derivation of mass density, particle shape, and particle size. J Atmos Solar Terrestrial Phys 2009;71:316-30.

[78] Hesse E, Mc Call DS, Ulanowski, Z, et al. Application of RTDF to particles with curved surfaces. JQSRT 2009;110:1599-603.

[79] Hill SC, Barber PW, Chowdhury, DQ, et al. Resonances and internal electric energy density in droplets. Proc SPIE 1991;1497:16-27.

[80] Hopkins RJ, Jones JW, Barrington, SJ, et al. Introducing depolarisation into an inexpensive, simple cloud sensor for standoff aerosol detection. Proc SPIE 2008;6972:697212.

[81] Hu R-M, Sokhi RS. Light scattering and absorption properties of dust particles retrieved from satellite measurements. JQSRT 2009;110:1698-705.

[82] Jayabalan J, Singh A, Chari, R, et al. Aggregated nanoplatelets: optical properties and optically induced deaggregation. J Phys Condens Matter 2008;20:445222.

[83] Kahnert M. Light scattering by particles with boundary symmetries. Light Scattering Rev 2008;3:69-107.

[84] Kalogerakis KS, Marschall J, Oza, AU, et al. The coating hypothesis for ammonia ice particles in Jupiter: laboratory experiments and optical modeling. Icarus 2008;196:202-15.

[85] Karlsson A, Bladh H, Bengtsson P-E. Accurate method for predicting light scattering from soot aggregates with subparticles of arbitrary shape and structure. J Opt Soc Am A 2009;26:1704-13.

[86] Khlebtsov NG. Determination of size and cocentration of gold nanoparticles from extinction spectra. Anal Chem 2008;80:6620-5.

[87] Khlebtsov NG. Optics and biophotonics of nanoparticles with a plasmon resonance. Quantum Electron 2008;38:504-29.

[88] Khlebtsov NG, Dykman LA. Optical properties and biomedical applications of plasmonic nanoparticles. JQSRT 2010;111:1-35.

[89] Khlebtsov N, Melnikov A, Shchyogolev, S, et al. Anisotropic and spectral properties of biological scattering objects with the ordered particle orientation. SPIE 1994;2082:33-42.

[90] Khlebtsov NG, Bogatyrev VA, Dykman LA, Melnikov AG. Spectral properties of colloidal gold and its conjugates with biospecific macromolecules. Proc SPIE 1996;2629:35-45.

[91] Khlebtsov BN, Khanadeyev VA, Verin DA, Khlebtsov NG. Optical properties of gold-nanoshell planar array. Proc SPIE 2007;6536:653602.

[92] Khlebtsov BN, Khanadeyev VA, Khlebtsov NG. Collective plasmon resonances in monolayers of metal nanoparticles and nanoshells. Opt Spectrosc 2008;104:282-94.

[93] Khlebtsov BN, Khanadeyev VA, Ye, J, et al. Coupled plasmon resonances in monolayers of metal nanoparticles and nanoshells. Phys Rev B 2008;77:035440.

[94] Khlebtsov BN, Khanadeev VA, Khlebtsov NG. Observation of extrahigh depolarized light scattering spectra from gold nanorods. J Phys Chem C 2008;112:12760-8.

[95] Knöner G, Nieminen TA, Parkin, S, et al. Calculation of optical trapping landscapes. Proc SPIE 2006;6326:63260K.

[96] Kolokolova LO, Zaitsev AL. Ground-based radar experiments for the study of radiation scattering by atmosphereless celestial bodies. Astron Astrophys Trans 1997;13:245-53.

[97] Kumjian MR, Ryzhkov AV. Storm-relative helicity revealed from polarimetric radar measurements. J Atmos Sci 2009;66:667-85.

[98] Kyurkchan AG, Demin DB. Solution of problem of electromagnetic waves scattering on inhomogeneously layered scatterers using pattern equation method. JQSRT 2009;110:1345-55.
[99] Kyurkchan AG, Skorodumova EA. Solving of problems of electromagnetic waves scattering by complex-shaped dielectric bodies via the pattern equations method. JQSRT 2009;110:1335-44.

[100] Lai HM, Leung PT, Young, K, et al. Time-independent perturbation for leaking electromagnetic modes in open systems with application to resonances in microdroplets. Phys Rev A 1990;41:5187-98.

[101] Lasue J, Levasseur-Regourd AC, Hadamcik E, Alcouffe G. Cometary dust properties retrievel from polarization observations: application to C/1995 01 Hale-Bopp and 1P/Halley. Icarus 2009; 199:129-44.

[102] Lattuada M, Ehrl L. Scattering properties of dense clusters of colloidal nanoparticles. J Phys Chem B 2009;113:5938-50.

[103] Lavigne C, Roblin A, Chervet P. Solar glint from oriented crystals in cirrus clouds. Appl Opt 2008;47:6266-76.

[104] Lee GW. Sources of errors in precipitation measurements by polarimetric radar: sensitivity of polarimetric parameters to drop deformation. J Korean Meteorol Soc 2007;43:41-57.

[105] Leijnse $H$, Uijlenhoet $R$, Stricker JNM. Microwave link rainfall estimation: effects of link length and frequency, temporal sampling, power resolution, and wet antenna attenuation. Adv Water Resour 2008;31:1481-93.

[106] Li L. Comment on "Optimized matrix inversion technique for the T-matrix method". Opt Lett 2008;33:1366.

[107] Liou KN, Gu Y, Lee, WL, et al. Some unsolved problems in atmospheric radiative transfer: implication for climate research in the Asia-Pacific region. In: Liou KN, Chou M-D, Hsu H-H, editors. Recent progress in atmospheric sciences. Applications to the AsiaPacific region. Hackensack, NJ: World Scientific; 2008. p. 307-25.

[108] Litvinov P. Derivation of extended boundary condition method from general definition of $T$-matrix elements and Lippman-Schwinger equation for transition operator. JQSRT 2008;109:1440-6.

[109] Liu G. A database of microwave single-scattering properties for nonspherical ice particles. Bull Am Meteorol Soc 2008;89:1563-70.

[110] Liu L, Mishchenko MI, Arnott WP. A study of radiative properties of fractal soot aggregates using the superposition $T$-matrix method. JQSRT 2008;109:2656-63.

[111] Loke VLY, Nieminen TA, Heckenberg NR, Rubinsztein-Dunlop H. Tmatrix calculation via discrete dipole approximation, point matching and exploiting symmetry. JQSRT 2009;110:1460-71.

[112] Mackowski DW, Mishchenko MI. Prediction of thermal emission and exchange among neighboring wavelength-sized spheres. J Heat Transfer 2008;130:112702.

[113] Maragò OM, Gucciardi PG, Bonaccorso, F, et al. Optical trapping of carbon nanotubes. Physica E 2008;40:2347-51.

[114] Markowicz KM, Flatau PJ, Kardas, AE, et al. Ceilometer retrieval of the boundary layer vertical aerosol extinction structure. J Atmos Oceanic Technol 2008;25:928-44

[115] Marzano FS, Scaranari D, Montopoli M, Vulpiani G. Supervised classification and estimation of hydrometeors from C-band dualpolarized radars: a Bayesian approach. IEEE Trans Geosci Remote Sens 2008;46:85-98.

[116] Matrosov SY. Assessment of radar signal attenuation caused by the melting hydrometeor layer. IEEE Trans Geosci Remote Sens 2008;46:1039-47.

[117] Matsumura M, Bastien P. Grain alignment in OMC1 as deduced from observed large circular polarization. Astrophys J 2009; 697:807-23.

[118] Mehta P, Harries JE, Turner DD. Effect of size distribution and particle shape on simulations of downwelling infrared spectra during Saharan dust storms. Am Inst Phys Conf Proc 2009; 1100:177-80.

[119] Merchiers O, Geffrin J-M, Vaillon, R, et al. Microwave analog to light scattering measurements on a fully characterized complex aggregate. Appl Phys Lett 2009;94:181107.

[120] Mishchenko MI. Multiple scattering, radiative transfer, and weak localization in discrete random media: unified microphysical approach. Rev Geophys 2008;46:RG2003.

[121] Mishchenko MI, Dlugach JM. Weak localization of electromagnetic waves and radar polarimetry of Saturn's rings. Mon Not R Astron Soc 2008;389:1665-74.

[122] Mishchenko MI, Dlugach JM. Radar polarimetry of Saturn's rings: modeling ring particles as fractal aggregates built of small ice monomers. JQSRT 2009;110:1706-12.

[123] Mishchenko MI, Liu L. Electromagnetic scattering by densely packed particulate ice at radar wavelengths: exact theoretical results and remote-sensing implications. Appl Opt 2009;48:2421-6.

[124] Mishchenko MI, Travis LD. Light scattering by size/shape distributions of nonspherical particles of size comparable to a wavelength. Proc SPIE 1993;1968:118-29. 
[125] Mishchenko MI, Travis LD, Mackowski DW. T-matrix computations of light scattering by large nonspherical particles: recent advances. Proc SPIE 1994;2309:72-83.

[126] Mishchenko MI, Travis LD, Lacis AA, Carlson BE. Satellite remote sensing of nonspherical tropospheric aerosols. Proc SPIE 1995;2311:150-61.

[127] Mishchenko MI, Dlugach JM, Liu, L, et al. Direct solutions of the Maxwell equations explain opposition phenomena observed for highalbedo solar system objects. Astrophys J Lett 2009;705:L118-22

[128] Mishra SK, Tripathi SN. Modeling optical properties of mineral dust over the Indian Desert. J Geophys Res 2008;113:D23201.

[129] Mishra SK, Dey S, Tripathi SN. Implications of particle composition and shape to dust radiative effect: a case study from the Great Indian Desert. Geophys Res Lett 2008;35:L23814.

[130] Molini L, Parodi A, Siccardi F. An observing system simulation experiment for the study on attenuation of C-band radar measurements. Meteorol Appl 2008;15:523-33.

[131] Moroz A. Depolarization field of spheroidal particles. J Opt Soc Am B 2009;26:517-27.

[132] Moumini N, Baravian C. Incoherent light transport in anisotropic media: form factor influence for oriented prolate ellipsoids. JQSRT 2009;110:1545-65.

[133] Mourant JR, Aida T, Coburn L, Ramachandran J. Effect of nonsphericity of scattering centers on light transport in turbid media. Proc SPIE 2004;5326:54-9.

[134] Narayanaswamy A, Chen G. Thermal near-field radiative transfer between two spheres. Phys Rev B 2008;77:075125.

[135] Nasiri SL, Kahn BH. Limitations of bispectral infrared cloud phase determination and potential for improvement. J Appl Meteorol Climatol 2008;47:2895-910.

[136] Nebuloni R, Capsoni C, Vigorita V. Quantifying bird migration by a high-resolution weather radar. IEEE Trans Geosci Remote Sens 2008;46:1867-75

[137] Nelson K, Deng Y. Effect of polycrystalline structure of $\mathrm{TiO}_{2}$ particles on the light scattering efficiency. J Colloid Interface Sci 2008;319:130-9.

[138] Nieminen TA, Heckenberg NR, Rubinsztein-Dunlop H. Forces in optical tweezers with radially and azimuthally polarized trapping beams. Opt Lett 2008;33:122-4.

[139] Nieminen TA, Asavei T, Loke, VLY, et al. Symmetry and the generation and measurement of optical torque. JQSRT 2009; 110:1472-82.

[140] Nousiainen T, Zubko E, Niemi, JV, et al. Single-scattering modeling of thin, birefringent mineral-dust flakes using the discrete-dipole approximation. J Geophys Res 2009;114:D07207.

[141] Okada Y. Efficient numerical orientation averaging of light scattering properties with a quasi-Monte-Carlo method. JQSRT 2008;109:1719-42.

[142] Okada Y, Kokhanovsky AA. Light scattering and absorption by densely packed groups of spherical particles. JQSRT 2009; 110:902-17.

[143] Okada Y, Mann I, Mukai T, Köhler M. Extended calculation of polarization and intensity of fractal aggregates based on rigorous method for light scattering simulations with numerical orientation averaging. JQSRT 2008;109:2613-27.

[144] Olmo FJ, Quirantes A, Lara, V, et al. Aerosol optical properties assessed by an inversion method using the solar principal plane for non-spherical particles. JQSRT 2008;109:1504-16

[145] Olofson KFG, Svensson EA, Witt G, Pettersson JBC. Arctic aerosol and clouds studied by bistatic lidar technique. J Geophys Res 2009;114:D18208.

[146] Onofri F, Ren KF, Grisolia C. Development of an in situ ITER dust diagnostic based on extinction spectrometry: dedicated light scattering models. J Nucl Mater 2009;390:1093-6.

[147] Osborne SR, Johnson BT, Haywood, JM, et al. Physical and optical properties of mineral dust aerosol during the dust and biomassburning experiment. J Geophys Res 2008;113:D00C03.

[148] Otto S, Bierwirth E, Weinzierl, B, et al. Solar radiative effects of a Saharan dust plume observed during SAMUM assuming spheroidal model particles. Tellus B 2009;61:270-96.

[149] Papanikolaou N, Gantzounis G, Stefanou N. Calculations of the optical response of metallodielectric nanostructures of nonspherical particles by a layer-multiple-scattering method. Proc SPIE 2008;6988:69881D.

[150] Paramonov LE. Light scattering by ensemble of nonspherical particles into solid angles. Proc SPIE 1994;2309:349-57.

[151] Pathak J, Michelangeli DV, Komguem, L, et al. Simulating Martian boundary layer water ice clouds and the lidar measurements for the Phoenix mission. J Geophys Res 2008;113:E00A05.
[152] Pecharromán C, Pérez-Juste J, Mata-Osoro, G, et al. Redshift of surface plasmon modes of small gold rods due to their atomic roughness and end-cap geometry. Phys Rev B 2008;77:035418.

[153] Pellegrini G, Mattei G, Bello V, Mazzoldi P. Local-field enhancement in metallic nanoplanets. Mater Sci Eng B 2008;149:247-50.

[154] Penninkhof JJ, Moroz A, van Blaaderen A, Polman A Optical properties of spherical and oblate spheroidal gold shell colloids. J Phys Chem C 2008;112:4146-50.

[155] Penninkhof JJ, Sweatlock LA, Moroz, A, et al. Optical cavity modes in gold shell colloids. J Appl Phys 2008;103:123105.

[156] Petrov D, Videen G, Shkuratov Yu, Kaydash M. Applications to spore detection of analytic Sh-matrix solution of light scattering from capsule and bi-sphere particles. Proc SPIE 2007;6733:673323.

[157] Petrov D, Shkuratov Yu, Videen G. Analytic light-scattering solution of two merging spheres using Sh-matrices. Opt Commun 2008;281:2411-23.

[158] Petrov D, Shkuratov Yu, Videen G. Sh-matrices method applied to light scattering by finite circular cylinders. JQSRT 2008;109:1474-95.

[159] Petrov D, Shkuratov Yu, Videen G. Reply to comment on "Optimized matrix inversion technique for the T-matrix method". Opt Lett 2008;33:1367.

[160] Petrov D, Shkuratov Yu, Videen G. Light scattering by a finite cylinder containing a spherical cavity using Sh-matrices. Opt Commun 2009;282:156-66.

[161] Petrov D, Shkuratov Yu, Videen G. The Sh-matrices method applied to light scattering by small lenses. JQSRT 2009;110: 1448-1459.

[162] Petrova EV, Tishkovets VP, Jockers K. Interaction of particles in the near field and opposition effects in regolith-like surfaces. Solar Syst Res 2009;43:100-15.

[163] Pfeifer M, Craig GC, Hagen M, Keil C. A polarimetric radar forward operator for model evaluation. J Appl Meteorol Climatol 2008;47: 3202-3220.

[164] Pinchuk AO. Angle dependent collective surface plasmon resonance in an array of silver nanoparticles. J Phys Chem A 2009;113:4430-6.

[165] Pitter MC, Hopcraft KI, Jakeman E, Walker JG. Measurement of polarization fluctuations in polydispersions of small spheroids. Proc SPIE 1999;3754:55-64.

[166] Pitts MC, Poole LR, Thomason LW. CALIPSO polar stratospheric cloud observations: second-generation detection algorithm and composition discrimination. Atmos Chem Phys 2009;9:7577-89.

[167] Qiu L, Larson TA, Smith, DK, et al. Single gold nanorod detection using confocal light absorption and scattering spectroscopy. IEEE Selected Top Quantum Electron 2007;13:1730-8.

[168] Qiu L, Vitkin E, Salahuddin, S, et al. Studying cells dynamics and function with CLASS microscopy. Proc SPIE 2008;6864:68640T

[169] Qiu L, Larson TA, Smith, D, et al. Observation of plasmon line broadening in single gold nanorods. Appl Phys Lett 2008;93: 153106.

[170] Quirantes A, Olmo FJ, Lyamani H, Alados-Arboledas L. Correction factors for a total scatter/backscatter nephelometer. JQSRT 2008;109:1496-503.

[171] Ramasubramanian M, Anthony S, Lambert J. Simplified spectraphotometric method for the detection of red blood cell agglutination. Appl Opt 2008;47:4094-105.

[172] Raut J-C, Chazette P. Radiative budget in the presence of multilayered aerosol structures in the framework of AMMA SOP-0. Atmos Chem Phys 2008;8:6839-64.

[173] Richardson JM, Aldridge JC, Milstein AB. Polarimetric lidar signatures for remote detection of biological warfare agents. Proc SPIE 2008;6972:69720E.

[174] Richardson JM, Aldridge JC, Milstein AB, Lacirignola JJ. Aerosol elastic scatter signatures in the near and mid-wave IR spectral regions. Proc SPIE 2009;7323:73230Q.

[175] Robert CE, von Savigny C, Burrows JP, Baumgarten G. Climatology of noctilucent cloud radii and occurrence frequency using SCIAMACHY. J Atmos Solar Terrestrial Phys 2009;71:408-23.

[176] Rother T. Green functions for plane wave scattering on single nonspherical particles. Light Scattering Rev 2009;4:121-66.

[177] Russell JE, Bantges RJ, Haigh, JD, et al. Retrieval of cirrus properties from high spectral resolution IR measurements. Proc SPIE 1998;3220:60-71.

[178] Sader JE, Pepperell CJ, Dunstan DE. Measurement of the optical properties and shape of nanoparticles in solution using Couette flow. ACS NANO 2008;2:334-40.

[179] Schleiss MA, Berne A, Uijlenhoet R. Geostatistical simulation of two-dimensional fields of raindrop size distributions at the meso$\gamma$ scale. Water Resour Res 2009;45:W07415. 
[180] Schmidt VA, Paramonov LE. Light scattering by ice hexagonal cylinders. Opt Atmos Ocean 2007;20:868-71 [in Russian].

[181] Schmidt V, Wriedt T. T-matrix method for biaxial anisotropic particles. JQSRT 2009;110:1392-7.

[182] Schmidt K, Wauer J, Rother T, Trautmann T. Scattering database for spheroidal particles. Appl Opt 2009;48:2154-64.

[183] Sebba DS, Lazarides AA. Robust detection of plasmon coupling in core-satellite nanoassemblies linked by DNA. J Phys Chem C 2008;112:18331-9.

[184] Sebba DS, Mock JJ, Smith, DR, et al. Reconfigurable core-satellite nanoassemblies as molecularly-driven plasmonic switches. Nano Lett 2008;8:1803-8.

[185] Shao S, Huang Y, Wei H, Rao R. Phase function of prolate spheroidic monodisperse aerosol particles. Acta Opt Sinica 2009;29:108-13.

[186] Sharma R, Balakrishnan N. Scattering from chiral composites. Proc SPIE 1998;3321:356-68.

[187] Sheppard BE, Joe PI. Performance of the precipitation occurrence sensor system as a precipitation gauge. J Atmos Oceanic Technol 2008;25:196-212.

[188] Si K, Gong W, Sheppard CJR. Model for light scattering in biological tissue and cells based on random rough nonspherical particles. Appl Opt 2009;48:1153-7.

[189] Simpson SH, Hanna S. Rotation of absorbing spheres in LaguerreGaussian beams. J Opt Soc Am A 2009;26:173-83.

[190] Simpson SH, Hanna S. Optical angular momentum transfer by Laguerre-Gaussian beams. J Opt Soc Am A 2009;26:625-38.

[191] Simpson SH, Benito DC, Hanna S. Calculation of optically-induced forces arising in conjunction with dynamic holographic assembly. Proc SPIE 2008;7038:70381E.

[192] Skorov YV, Keller HU, Rodin AV. Optical properties of aerosols in Titan's atmosphere. Planet Space Sci 2008;56:660-8.

[193] Somekawa T, Yamanaka C, Fujita M, Galvez MC. Simultaneous three-wavelength depolarization measurements of clouds and aerosols using a coherent white light continuum. J Appl Phys 2008;103:043101.

[194] Somekawa T, Yamanaka C, Fujita M, Galvez MC. A new concept to characterize nonspherical particles from multi-wavelength depolarization ratios based on $T$-matrix computation. Part Part Syst Charact 2008;25:49-53.

[195] Spek ALJ, Unal CMH, Moisseev, DN, et al. A new technique to categorize and retrieve the microphysical properties of ice particles above the melting layer using radar dual-polarization spectral analysis. J Atmos Oceanic Technol 2008;25:482-97.

[196] Sreerekha TR, Buehler SA, O'Keeffe, U, et al. A strong ice cloud event as seen by a microwave satellite sensor: simulations and observations. JQSRT 2008;109:1705-18.

[197] Stefanou N, Gantzounis G, Tserkezis C. Multiple-scattering calculations for plasmonic nanostructures. Int J Nanotechnol 2009;6:137-63.

[198] Stout B, Auger JC, Devilez A. Recursive $T$ matrix algorithm for resonant multiple scattering: applications to localized plasmon excitations. J Opt Soc Am A 2008;25:2549-57.

[199] Tanaka Y, Yoshikawa H, Itoh T, Ishikawa M. Surface enhanced Raman scattering from pseudoisocyanine on Ag nanoaggregates produced by optical trapping with a linearly polarized laser beam. J Phys Chem C 2009;113:11856-60.

[200] Thomas ME, Airola MB, Carter CC, Boggs NT. Extinction and backscatter cross sections of biological materials. Proc SPIE 2007;6554:65540Q.

[201] Thomas ME, Hahn DV, Carr, AK, et al. Extinction and backscatter cross sections of biological materials. Proc SPIE 2008; 6954:69540Y.

[202] Thomson FS, Marouf EA. Diffraction theory modeling of nearforward radio wave scattering from particle clusters. Icarus 2009;204:290-302.

[203] Thurai M, Bringi VN. Calculations of cross-polar discrimination spread for $20 \mathrm{GHz}$ fixed satellite systems using rain microstructure information. Radio Sci 2009;44:RS4006.

[204] Thurai M, Bringi VN, Petersen WA. Rain microsctructure retrievals using 2-D video disdrometer and C-band polarimetric radar. Adv Geosci 2009;20:13-8.

[205] Tishkovets VP. Radiation diffuse scattering by a densely packed layer of spherical partcles. Radiofiz Radioastron 2007;12:43-54 [in Russian].

[206] Tishkovets VP. Light scattering by closely packed clusters: shielding of particles by each other in the near field. JQSRT 2008;109:2665-72.

[207] Tishkovets VP. Mutual shielding of particles in the near field. Radiofiz Radioastron 2008;13:236-49 [in Russian].
[208] Tomasko MG, Doose L, Engel, S, et al. A model of Titan's aerosols based on measurements made inside the atmosphere. Planet Space Sci 2008;56:669-707.

[209] Travis K, Aaron J, Harrison N, Sokolov K. Phenomenology of optical scattering from plasmonic aggregates for application to biological imaging and clinical therapeutics. Proc SPIE 2008;6869:68690H.

[210] Tseng SH, Huang B. Comparing Monte Carlo simulation and pseudospectral time-domain numerical solutions of Maxwell's equations of light scattering by a macroscopic random medium. Appl Phys Lett 2007;91:051114.

[211] Tserkezis C, Papanikolaou N, Almpanis E, Stefanou N. Tailoring plasmons with metallic nanorod arrays. Phys Rev B 2009;80:125124

[212] Tsukerman I, Čajko F, Sokolov AP. Traditional and new simulation techniques for nanoscale optics and photonics. Proc SPIE 2005;5927:59270L

[213] Tsukerman I, Čajko F, Sokolov AP. Traditional and new simulation techniques for plasmon nanoparticles and photonic crystals. Proc SPIE 2006:6180:61800N.

[214] Tyynelä J, Nousiainen T, Göke S, Muinonem K. Modeling C-band single scattering properties of hydrometeors using discrete-dipole approximation and T-matrix method. JQSRT 2009;110:1654-64.

[215] Ulanowski Z, Bailey J, Lucas, PW, et al. Alignment of atmospheric mineral dust due to electric field. Atmos Chem Phys 2007;7:6161-73.

[216] Vaidya DB, Gupta R. Composite grains: effects of porosity and inclusions on the $10 \mu \mathrm{m}$ silicate feature. JQSRT 2009;110:1726-32.

[217] Vargas WE. Aggregation and composition effects on absorption and scattering properties of dye-sensitized anatase $\mathrm{TiO}_{2}$ particle clusters. JQSRT 2008;109:1693-704.

[218] Velazco-Roa MA, Dzhongova E, Thennadil SN. Complex refractive index of nonspherical particles in the visible near infrared region-application to Bacillus subtilis spores. Appl Opt 2008;47:6183-9.

[219] Vincendon M, Langevin Y, Poulet, F, et al. Yearly and seasonal variations of low albedo surfaces on Mars in the OMEGA/MEx dataset: constraints on aerosols properties and dust deposits. Icarus 2009;200:395-405

[220] Vinokurov A, Farafonov V, Il'in V. Separation of variables method for multilayered nonspherical particles. JQSRT 2009;110:1356-68.

[221] Voit F, Schäfer J, Kienle A. Light scattering by multiple spheres: comparison between Maxwell theory and radiative-transfertheory calculations. Opt Lett 2009;34:2593-5.

[222] von Savigny C, Robert CE, Baumgarten, G, et al. Comparison of NLC particle sizes derived from SCIAMACHY/Envisat observations with ground-based LIDAR measurements at ALOMAR $\left(69^{\circ} \mathrm{N}\right)$. Atmos Meas Tech 2009;2:523-31.

[223] Voshchinnikov NV, Il'in VB, Stognienko R. Comparative analysis of different solutions of light scattering problem for non-spherical particles. Proc SPIE 1994;2309:89-97.

[224] Vulpiani G, Marzano FS. Advanced techniques for polarimetric radar estimation of rainfall. In: Sorooshian, S, editor. Hydrological modelling and the water cycle. Berlin: Springer; 2008. p. 69-92.

[225] Vulpiani G, Tabary P, du Chatelet JP, Marzano FS. Comparison of advanced radar polarimetric techniques for operational attenuation correction at C band. J Atmos Oceanic Technol 2008;25:1118-35.

[226] Wagner R, Benz S, Möhler, O, et al. Influence of particle aspect ratio on the midinfrared extinction spectra of wavelength-sized ice crystals. J Phys Chem A 2007;111:13003-22.

[227] Wagner R, Linke C, Naumann, K-H, et al. A review of optical measurements at the aerosol and cloud chamber AIDA. JQSRT 2009;110:930-49.

[228] Wähnert M, Radünz R, Cichos F. Nanoscale distance fluctuations probed by photothermal correlation spectroscopy. Proc SPIE 2009;7185:71850V.

[229] Wang T, Huang J. A method for estimating optical properties of dusty cloud. Chin Opt Lett 2009;7:368-72.

[230] Wang X-Y, Ruan L-M, Oi H, Wang S-G. Scattering properties of nonspherical particles. J Eng Thermophys 2009;30:1366-8.

[231] Waterman PC. T-matrix methods in acoustic scattering. J Acoust Soc Am 2009; 125:42-51.

[232] Wauer J, Rother T. Considerations to Rayleigh's hypothesis. Opt Commun 2009:282:339-50.

[233] Wheeler MS, Aitchison JS, Chen, JIL, et al. Infrared magnetic response in a random silicon carbide micropowder. Phys Rev B 2009;79:073103.

[234] Wiegner M, Gasteiger J, Kandler, K, et al. Numerical simulations of optical properties of Saharan dust aerosols with emphasis on lidar applications. Tellus B 2009;61:180-94. 
[235] Wolff MJ, Smith MD, Clancy, RT, et al. Wavelength dependence of dust aerosol single scattering albedo as observed by the compact reconnaissance imaging spectrometer. J Geophys Res 2009; 114:E00D04.

[236] Wriedt T, Schuh R. Decompositioning method to compute scattering by complex shaped particles using a multiple scattering T-matrix approach. JQSRT 2008;109:2315-28.

[237] Wriedt T, Schuh R, Doicu A. Scattering by aggregated fibres using a multiple scattering $T$-matrix approach. Part Part Syst Charact 2008;25:74-83.

[238] Yadav MK, Sharma SK. On the validity of Rayleigh-Gans-Debye type approximations in red blood cell size determination. J Mod Opt 2008;55:921-9.

[239] Yan S, Yao B. Fast calculation technique for scattering in $T$-matrix method. Phys Lett A 2008;372:5243-5.

[240] Yan WZ, Du Y, Wu H, Liu DW. EM scattering from a long dielectric circular cylinder. Prog Electromagn Res 2008;85:39-67.

[241] Yan WZ, Du Y, Li, ZY, et al. Characterization of the validity region of the extended $T$-matrix method for scattering from dielectric cylinders with finite length. Prog Electromagn Res 2009;96:309-28.

[242] Yip W, Li X. Multiple scattering effects on optical characterization of biological tissue using spectroscopic scattering parameters. Opt Lett 2008;33:2877-9.

[243] Yu HK, Yi G-R, Kang, J-H, et al. Surfactant-assisted synthesis of uniform titania microspheres and their clusters. Chem Mater 2008;20:2704-10.

[244] Zaccone A, Wu H, Lattuada M, Morbidelli M. Correlation between colloidal stability and surfactant adsorption/association phenomena studied by light scattering. J Phys Chem B 2008;112:1976-86.

[245] Zahiri E-P, Gosset M, Lafore J-P, Gouget V. Use of a radar simulator on the output fields from a numerical mesoscale model to analyze X-band rain estimators. J Atmos Oceanic Technol 2008;25:341-67.

[246] Zardini AA, Krieger UK. Evaporation kinetics of a non-spherical, levitated aerosol particle using optical resonance spectroscopy for precision sizing. Opt Express 2009;17:4659-69.

[247] Zeng N, Murphy AB. Heat generation by optically and thermally interacting aggregates of gold nanoparticles under illumination. Nanotechnology 2009;20:375702.
[248] Zhang Y, Palmer R, Zhang, G, et al. Multi-functional airborne external hazard monitoring radar with antenna diversity. Proc SPIE 2008;7088:70880F.

[249] Zhao Y, Ma L. Assessment of two fractal scattering models for the prediction of the optical characteristics of soot aggregates. JQSRT 2009; 110:315-22.

[250] Zhao Y, Ma L. Applicable range of the Rayleigh-Debye-Gans theory for calculating the scattering matrix of soot aggregates. Appl Opt 2009;48:591-7.

[251] Zinevich A, Messer H, Alpert P. Frontal rainfall observation by a commercial microwave communication network. J Appl Meteorol Climatol 2009;48:1317-34.

[252] Rother T. Electromagnetic wave scattering on nonspherical particles: basic methodology and simulations. Berlin: Springer; 2009.

[253] Dolan B, Rutledge SA. A theory-based hydrometeor indentification algorithm for X-band polarimetric radars. J Atmos Oceanic Technol 2009;26:2071-88.

[254] Bringi VN, Williams CR, Thurai M, May PT. Using dual-polarization radar and dual-frequency profiler for DSD characterization: a case study from Darwin, Australia. J Atmos Oceanic Technol 2009;26:2107-22

[255] Venkata PG, Aslan MM, Mengüç MP, Videen G. Surface plasmon scattering by gold nanoparticles and two-dimensional agglomerates. J Heat Transfer 2007;129:60-70.

[256] Charnigo R, Francoeur M, Mengüç, MP, et al. Derivatives of scattering profiles: tools for nanoparticle characterization. J Opt Soc Am A 2007;24:2578-89.

[257] Mishchenko MI, Travis LD, Lacis AA. Scattering, absorption, and emission of light by small particles. Cambridge: Cambridge University Press; 2002 Available in the PDF format at $\langle$ http:/ www.giss.nasa.gov/staff/mmishchenko/publications/ $>$.

[258] Doicu A, Wriedt T, Eremin YuA. Light scattering by systems of particles. Null-field method with discrete sources: theory and programs. Berlin: Springer; 2006.

[259] Borghese F, Denti P, Saija R. Scattering from model nonspherical particles. Theory and applications to environmental physics. Berlin: Springer; 2007.

[260] Waterman PC. Symmetry, unitarity, and geometry in electromagnetic scattering. Phys Rev D 1971;3:825-39. 